\title{
A Low Voltage, Rail-to-Rail, Class AB CMOS Amplifier With High Drive and Low Output Impedance Characteristics
}

Gabriel A. Rincon-Mora, Member, IEEE, and Richard Stair, Member, IEEE

Abstract-- This paper describes a CMOS rail-to-rail class AB operational amplifier designed to have extremely low output impedance and large current-drive capability. The amplifier uses an innovative output stage, having both source follower and common source stages working simultaneously throughout the output common-mode range. The source follower ensures low output impedance, which enables it to drive relatively large load capacitors, while the common-source gain stage provides high current drive. Furthermore, the circuit is fully functional with supplies as low as $1.5 \mathrm{~V}$. The amplifier is capable of driving a maximum output current of $\pm 7 \mathrm{~mA}$ with only $140 \mu \mathrm{A}$ of quiescent current, making it power efficient and, therefore, appropriate for low voltage battery-powered applications.

Index Terms-- Class AB, rail-to-rail, low output impedance, low voltage, operational amplifier, power efficient. 


\section{I - INTRODUCTION}

Class $\mathrm{AB}$ output stages are increasingly popular in today's low voltage battery-powered electronics where amplifier applications demand high efficiency as well as rail-to-rail operation. In the era of portable equipment, low supply voltage and low power consumption are intrinsic traits [1]. Performance requirements are also becoming more stringent, leaving the designer with more difficult specifications to fulfill and less flexibility with which to do it. For instance, low output impedance is generally desired, but classical source-follower configurations are not allowed in low voltage applications. Dynamic range is already limited by low battery voltages and source followers take too much of that range away to be viable solutions. In fact, most low voltage class $\mathrm{AB}$ output stages have inherently high output impedance because they necessarily employ common-source configurations [2-4]. On the other hand, amplifiers with source follower output stages typically suffer from output voltage swing limitations, which are severe in low voltage applications. Ideally, though, one would like to combine the characteristics of sourcefollowers and common-source gain stages in the same circuit to achieve low output impedance, rail-to-rail operation, and high current-drive capability. The one previously reported topology that implements this combination is not a low voltage solution and, moreover, has load-range limitations [5]. The amplifier described in this paper, however, combines common-source gain stages and source-followers to achieve true class $\mathrm{AB}$ operation with low output impedance while still producing a rail-to-rail output voltage swing. In light of today's market, the amplifier is designed to operate with low supply voltages and low quiescent current.

The basic circuit topology of the proposed amplifier is presented in Section II. Section III discusses the circuit realization, detailing the input stage, the gain stage, and the output stage. Common-mode feedback, rail-to-rail control, and compensation are also discussed in this section 
while highlighting optimum operating conditions. In Section IV, simulated results are presented and discussed. The circuit is subsequently compared to other state-of-the-art designs. Finally, conclusions are drawn in Section V.

\section{II - PRoposed ARCHITECTURE}

The basic circuit topology of the class AB amplifier is shown in Fig. 1. The voltage amplifier with gain $A_{V}$ drives the output stage with separate dual in-phase signals. The output stage consists of a high side driver (HSD) circuit, which is capable of sourcing large amounts of current to load $\mathrm{Z}_{\mathrm{L}}$, and a low side driver (LSD) circuit, capable of sinking large amounts of load current. The high current devices, $\mathrm{M}_{\mathrm{PD}}$ in the HSD and $\mathrm{M}_{\mathrm{ND}}$ in the LSD, are connected in a common-source configuration, allowing the output to reach the supply rails as in most lowvoltage class $\mathrm{AB}$ output stages. In this output stage, however, the output is also connected to source-followers. Both the HSD and the LSD circuits are closed-loop feedback networks. The two feedback loops lower the effective output impedance of the output stage, already the reciprocal of the transconductance, by approximately the loop gain. The Common-Mode Feedback (CMFB) circuit insures that the drivers operate in true class $\mathrm{AB}$ mode. It performs this task by sensing the respective output currents and feeding a control signal back to the main forward loop. The CMFB circuit essentially controls the quiescent biasing conditions of the power transistors.

Fig. 2(a) shows a more detailed circuit diagram of the LSD circuit, without the CMFB portion. Current $I_{1}$ is designed to be greater than $I_{2}$. Then, assuming all devices are biased in the saturation region, the current difference, $\mathrm{I}_{1}-\mathrm{I}_{2}$, flows through source-follower transistor $\mathrm{M}_{\mathrm{NF}}$ and into driver transistor $\mathrm{M}_{\mathrm{ND}}$. Unlike most class $\mathrm{AB}$ output stages, the gate of the high current 
transistor is controlled indirectly through the feedback loop, which is comprised of $\mathrm{M}_{\mathrm{NF}}, \mathrm{M}_{\mathrm{PB}}$, and $\mathrm{M}_{\mathrm{ND}}$.

To demonstrate how the feedback loop operates, a fast transient decrease in voltage at $V_{\text {IN }}$ is considered. When $V_{\text {IN }}$ decreases, more of $I_{1}$ is steered into $M_{P B}$, thereby increasing the voltage at the gate of $\mathrm{M}_{\mathrm{ND}}$ which, in turn, causes $\mathrm{M}_{\mathrm{ND}}$ to sink additional current. Subsequently, $\mathrm{V}_{\text {OUT }}$ is lowered until the gate-source voltage of $\mathrm{M}_{\mathrm{NF}}$ once again reaches its steady-state value. The overall result, with respect to forward gain, is that the driver circuit behaves similarly to a simple source-follower transistor. One important difference exists, however, in that the output impedance is roughly two orders of magnitude below that of a classical source-follower. Fig. 2(b) shows the ac equivalent circuit used to determine the output resistance, which is given by

$$
\text { Ro }=\frac{V_{t}}{I t}=\frac{V_{t}}{g_{m F} V_{t}+g_{m F} V_{t} r_{o 2} g_{m D}}=\frac{1}{g_{m F}\left(1+g_{m D} r_{o 2}\right)},
$$

where $V_{t}$ is an ac test voltage applied to the output, $I_{t}$ is the corresponding test current, $g_{m F}$ is the transconductance of $\mathrm{M}_{\mathrm{NF}}, \mathrm{r}_{\mathrm{o} 2}$ is the output resistance of current source $\mathrm{I}_{2}$, and $\mathrm{g}_{\mathrm{mD}}$ is the transconductance of $\mathrm{M}_{\mathrm{ND}}$. The feedback loop effectively reduces the output impedance of the driver, already $1 / \mathrm{g}_{\mathrm{mF}}$, by a factor of $\left(1+\mathrm{g}_{\mathrm{mD}} \mathrm{r}_{\mathrm{o}}\right)$. The ac and dc analysis of the high side driver is analogous to the LSD counterpart.

To drive the HSD and LSD, dual in-phase signals are required. With the help of the CMFB circuit and replication circuits in the input and gain stages, these two signals are generated. The following section describes the circuit operation of each stage.

\section{III - CIRCUIT IMPLEMENTATION}

The complete circuit diagram for the class $\mathrm{AB}$ amplifier, including the input stage, gain stage, output drivers, and CMFB circuit is shown in Fig. 3. The circuit is biased from a $2 \mu \mathrm{A}$ current source, which flows through bias resistor $\mathrm{R}_{\mathrm{B} 1}$ and is mirrored to flow through bias 
resistor $R_{B 2}$. These resistors provide dc bias voltages for cascode transistors throughout the entire circuit. They are designed to provide enough headroom from either supply rail to insure that all current sources stay in the saturation region, provided that the rail-to-rail supply voltage is greater than about $1.5 \mathrm{~V}$.

\section{A. Input Stage}

The input stage of the operational amplifier is similar to the bipolar input stage reported in [6]. It allows rail-to-rail input common-mode range with supply voltages as low as about 1.5 V. Since a detailed analysis of a similar input stage is presented in [6], only a brief intuitive description is offered here. Fig. 4 shows a simplified diagram of the input stage. The PMOS and the NMOS differential input pairs operate in parallel. Three regions of input common-mode operation exist. These include when the input voltage is (1) low enough such that only the PMOS differential pair conducts, (2) high enough such that only the NMOS pair conducts, and (3) in the transition region where both differential pairs conduct current. The PMOS pair accommodates input voltages down to the negative supply, while the NMOS counterpart handles input voltages up to the positive supply.

Both input pairs conduct current in the transition region, so long as the total supply voltage is greater than about $2 \mathrm{~V}$. For supply voltages above $2 \mathrm{~V}$, current $\mathrm{I}_{\mathrm{X}}$ in Fig. 4 is zero. The common-mode input signal determines the state of current $\mathrm{I}_{\mathrm{X}}$ by turning it on only when both differential pairs approach their common-mode range limits, a state that is determined by the reference voltages impressed on resistors $R_{V 1}$ and $R_{V 2}$ in Fig. 3. In other words, only when both differential pairs' current sources approach the triode region will current $\mathrm{I}_{\mathrm{X}}$ be established. For example, if the supply voltage is $4 \mathrm{~V}$, either or both $\mathrm{M}_{\mathrm{P} 013}$ and $\mathrm{M}_{\mathrm{N} 011}$ would be cut off since 
both NMOS and PMOS differential pair current source voltages cannot simultaneously approach their triode regions.

For the case of lower supply voltages, level-shift voltages are developed across resistors $\mathrm{R}_{\mathrm{S} 1}$ through $\mathrm{R}_{\mathrm{S} 4}$. If the supply voltage is $1.5 \mathrm{~V}$ and the input voltage is $0.7 \mathrm{~V}$, for example, both $\mathrm{M}_{\mathrm{P} 013}$ and $\mathrm{M}_{\mathrm{N} 011}$ conduct current and $\mathrm{I}_{\mathrm{X}}$ is established. For the NMOS pair, the resulting input common-mode voltage is increased thereby insuring proper operation with the given headroom. Similarly, the effective input common-mode voltage of the PMOS pair is decreased. The input resistance of the amplifier remains high because the current sourced into the resistors is simultaneously sunk at the other end. Level shifting the inputs circumvents the condition near the middle of the input range where both input pairs are non-operational, which occurs when

$$
\mathrm{V}_{\mathrm{CC}}-\mathrm{V}_{\mathrm{SS}}<\mathrm{V}_{\mathrm{TN}}+\mathrm{V}_{\mathrm{TP}}+4 \mathrm{~V}_{\mathrm{DS}} \text {. }
$$

Comparators $\mathrm{M}_{\mathrm{N} 011}-\mathrm{M}_{\mathrm{N} 012}$ and $\mathrm{M}_{\mathrm{P} 013}-\mathrm{M}_{\mathrm{P} 014}$ in Fig. 3 dynamically control the actual magnitude of the level-shift voltage by transferring the appropriate amount of $\mathrm{M}_{\mathrm{P} 06}$ 's current into the levelshift resistors. The input impedance of the input stage, in the end, is only compromised by the mirroring inaccuracies of $\mathrm{M}_{\mathrm{P} 08}, \mathrm{M}_{\mathrm{P} 03}, \mathrm{M}_{\mathrm{N} 03}$, and $\mathrm{M}_{\mathrm{N} 04}$, resulting from channel-length modulation effects and transistor mismatches [6].

The input stage also includes circuitry to stabilize transconductance over the commonmode input range. Transistor $\mathrm{M}_{\mathrm{P} 09}$ in Fig. 3 senses the input voltage and functions as a currentsteering switch to regulate the amount of tail current in each input pair. At common-mode input voltages near $\mathrm{V}_{\mathrm{SS}}, \mathrm{M}_{\mathrm{P} 09}$ is off, and all of $\mathrm{M}_{\mathrm{P} 02}$ 's current flows into the PMOS pair. Conversely, at input voltages near $\mathrm{V}_{\mathrm{CC}}, \mathrm{M}_{\mathrm{P} 09}$ conducts and transfers all of $\mathrm{M}_{\mathrm{P} 02}$ 's current to the NMOS pair via $\mathrm{M}_{\mathrm{N} 06}$ and $\mathrm{M}_{\mathrm{N} 07}$. This topology is commonly used in bipolar rail-to-rail input stages to achieve constant transconductance over the common-mode input range. In CMOS circuits, 
however, the resulting transconductance is not constant because of the nonlinear dependence of transconductance upon quiescent current. Instead, the transconductance varies by the square root of two over the entire input range. This is less variation than constant current rail-to-rail CMOS input stages, such as the one reported in [7]. The circuit transconductance is given by

$$
\mathrm{g}_{\mathrm{m}}=\left\{\begin{array}{cc}
\sqrt{\mathrm{I} \beta} & \uparrow \mathrm{ICMR} \\
\sqrt{2} \sqrt{\mathrm{I} \beta} & \text { transition region, } \\
\sqrt{\mathrm{I} \beta} & \downarrow \mathrm{ICMR}
\end{array}\right.
$$

where $\beta_{\mathrm{N}}$ is made to equal $\beta_{\mathrm{P}}\left(\beta=\mathrm{k}^{\prime} \mathrm{W} / \mathrm{L}\right)$.

\section{B. Gain Stage}

The amplifier uses a folded-cascode current-summing gain stage with two output branches to provide dual in-phase output voltages for the class $A B$ output stage. The gain stage consists of cascode transistors $\mathrm{M}_{\mathrm{P} 12}-\mathrm{M}_{\mathrm{P} 14}$ and $\mathrm{M}_{\mathrm{N} 13}-\mathrm{M}_{\mathrm{N} 15}$ along with current sources $\mathrm{M}_{\mathrm{P} 10}, \mathrm{M}_{\mathrm{P} 11}$ and $\mathrm{M}_{\mathrm{N} 10}-\mathrm{M}_{\mathrm{N} 12}$. The output currents from the PMOS and the NMOS input pairs are split by $\mathrm{M}_{\mathrm{P} 011}, \mathrm{M}_{\mathrm{P} 012}$ and $\mathrm{M}_{\mathrm{P} 13}, \mathrm{M}_{\mathrm{P} 14}$, respectively, and are summed into the gain stage's high impedance output nodes, the dominant high impedance nodes of the main loop.

\section{Output Stage with Common Mode Feedback}

The inputs to the high side and low side output drivers in Fig. 3 are the gates of $\mathrm{M}_{\mathrm{PF}}$ and $\mathrm{M}_{\mathrm{NF}}$, respectively. Current sources $\mathrm{M}_{\mathrm{P} 210}$ and $\mathrm{M}_{\mathrm{P} 211}$ bias the low side driver while $\mathrm{M}_{\mathrm{N} 215}$ and $\mathrm{M}_{\mathrm{N} 216}$ bias the high side driver, as discussed in Section II. The gates of bias transistors $\mathrm{M}_{\mathrm{NB}}$ and $\mathrm{M}_{\mathrm{PB}}$ are tied to the same bias points as the cascode transistors in the amplifier gain stage. The outputs of the drivers share a common connection, which is the output of the operational amplifier.

A simplified diagram of the common-mode feedback circuit is shown in Fig. 5. Currentcontrolled currents $\mathrm{I}_{\mathrm{DP}}$ and $\mathrm{I}_{\mathrm{DN}}$ sink currents proportional to the driver currents, forcing them to 
flow through resistors $\mathrm{R}_{\mathrm{CMN}}$ and $\mathrm{R}_{\mathrm{CMP}}$. The source follower pair, biased from $\mathrm{I}_{\mathrm{CM} 1}$, senses the lower of the two currents, in the form of voltages across resistors $\mathrm{R}_{\mathrm{CMN}}$ and $\mathrm{R}_{\mathrm{CMP}}$, and directs the signal to the input of amplifier $A_{v}$. The amplifier, in turn, compares this voltage to a reference voltage and feeds back an error signal to the gain stage. In a steady-state no-load condition, the voltage drops across $R_{C M N}$ and $R_{C M P}$ are roughly equal, indicating equal amounts of current through both drivers. In this case, both $\mathrm{M}_{\mathrm{NCM} 1}$ and $\mathrm{M}_{\mathrm{NCM} 2}$ conduct current and insure class $\mathrm{AB}$ operation. When the output stage is sourcing or sinking load current, the voltage drops across $\mathrm{R}_{\mathrm{CMN}}$ and $\mathrm{R}_{\mathrm{CMP}}$ are not equal. The voltage imbalance causes the source follower corresponding to the larger voltage drop to cut off. The loop then, in essence, regulates to the lower of the two currents to a point established by $\mathrm{I}_{\mathrm{CM} 2}$. The magnitude of the steady-state driver quiescent current is thus determined by the current flowing through $\mathrm{R}_{\mathrm{CMR}}$ and $\mathrm{M}_{\mathrm{NCMR}}$. Transistors $\mathrm{M}_{\mathrm{NCMR}}$, $\mathrm{M}_{\mathrm{NCMN}}$, and $\mathrm{M}_{\mathrm{NCMP}}$ are designed to nominally have equal gate-source voltages. Consequently, the common-mode feedback circuit forces the voltage across $\mathrm{R}_{\mathrm{CMN}}$ or $\mathrm{R}_{\mathrm{CMP}}$ to be equal to the voltage across reference resistor $\mathrm{R}_{\mathrm{CMR}}$.

In Fig. 3, dependent current sources $\mathrm{I}_{\mathrm{DP}}$ and $\mathrm{I}_{\mathrm{DN}}$ correspond to $\mathrm{M}_{\mathrm{N} 26}$ and $\mathrm{M}_{\mathrm{NDS}}$, and are current mirrors designed to reproduce a small fraction of the driver currents $\left(\mathrm{M}_{\mathrm{ND}}\right.$ and $\left.\mathrm{M}_{\mathrm{PD}}\right)$. Device $\mathrm{M}_{\mathrm{NDS}}$ mirrors $\mathrm{M}_{\mathrm{ND}}$ 's current and $\mathrm{M}_{\mathrm{PDS}}$ mirrors $\mathrm{M}_{\mathrm{PD}}$ 's current, which is turned around by current mirror $\mathrm{M}_{\mathrm{N} 25}-\mathrm{M}_{\mathrm{N} 26}$ before being applied to $\mathrm{R}_{\mathrm{CMP}}$. The CMFB amplifier is made up of input pair $\mathrm{M}_{\mathrm{P} 26}$ and $\mathrm{M}_{\mathrm{P} 29}$, with common-mode transistors $\mathrm{M}_{\mathrm{P} 27}$ and $\mathrm{M}_{\mathrm{P} 28}$ for biasing. The differential outputs of the error amplifier force a differential current back into the gain stage, thereby modulating the voltage at the inputs of the HSD and LSD circuits and controlling the driver currents. 


\section{Rail-to-Rail Control}

In the HSD, if the output voltage is near the high end of the output voltage range, the HSD functions normally, and the common-mode feedback signal propagates through the source follower and the localized feedback loop to control the driver current. However, as the output voltage decreases, the HSD input p-type source-follower $\mathrm{M}_{\mathrm{PF}}$ cuts off, breaking the HSD loop. Just before this happens, then, the common-mode error signal must have an alternative path to control the driver current $\left(\mathrm{M}_{\mathrm{PD}}\right)$; otherwise, $\mathrm{CMFB}$ control is lost. Transistors $\mathrm{M}_{\mathrm{N} 217}-\mathrm{M}_{\mathrm{N} 219}$ and $\mathrm{M}_{\mathrm{P} 23}-\mathrm{M}_{\mathrm{P} 24}$ provide this alternative path. $\mathrm{M}_{\mathrm{N} 217}$ senses the voltage at the input of the HSD and, when the output voltage is approximately $1.5 \mathrm{~V}$ above $\mathrm{V}_{\mathrm{SS}}$, the gate-source voltage of $\mathrm{M}_{\mathrm{N} 217}$ is large, $\mathrm{M}_{\mathrm{P} 24}$ is off, and the HSD circuit operates normally, as previously discussed. On the other hand, when the output is within $1.5 \mathrm{~V}$ of $\mathrm{V}_{\mathrm{SS}}, \mathrm{M}_{\mathrm{N} 217}$ starts to conduct less current and, at the point where its current is less than that of $\mathrm{M}_{\mathrm{P} 22}$, transistors $\mathrm{M}_{\mathrm{N} 218}, \mathrm{M}_{\mathrm{N} 219}, \mathrm{M}_{\mathrm{P} 23}$, and $\mathrm{M}_{\mathrm{P} 24}$ start conducting current. An alternative signal path is therefore generated and control of $\mathrm{M}_{\mathrm{PD}}$ is guaranteed throughout the output voltage range. Device $\mathrm{M}_{\mathrm{N} 217}$ is sized such that this condition occurs just before $\mathrm{M}_{\mathrm{PF}}$ turns off such that the alternative signal path exists before the source follower path desists. In the end, $\mathrm{M}_{\mathrm{N} 217}$ functions as a linear transconductance amplifier when the output voltage is below $1.5 \mathrm{~V}$. A complementary control circuit is similarly used in the LSD counterpart.

\section{E. Compensation}

Since the amplifier topology consists of a single high-impedance gain stage, the dominant low frequency pole must be the high-impedance node. Two of these nodes exist in this case, at the gates of $\mathrm{M}_{\mathrm{NF}}$ and $\mathrm{M}_{\mathrm{PF}}$, but these operate in parallel, so they may be treated as a single node 
for this analysis. Compensation capacitors $\mathrm{C}_{\mathrm{C} 2}$ and $\mathrm{C}_{\mathrm{C} 3}$ are placed on these nodes to the supplies to insure that these nodes are the dominant poles in the main feedback loop.

The output constitutes the second non-dominant pole. Its frequency is determined by the load capacitor and the effective output impedance, as defined in Equation (1) and given by

$$
\mathrm{p}_{2} \approx \frac{1}{2 \pi\left(\operatorname{Ro}_{\mathrm{LSD}} \| \mathrm{Ro}_{\mathrm{HSD}}\right) \mathrm{C}_{\mathrm{L}}},
$$

where

$$
\mathrm{Ro}_{\mathrm{LSD}} \approx \frac{1}{\mathrm{~g}_{\mathrm{mNF}} \mathrm{g}_{\mathrm{mND}} \mathrm{r}_{\mathrm{ds}-\mathrm{N} 20}}
$$

and

$$
\mathrm{Ro}_{\mathrm{HSD}} \approx \frac{1}{\mathrm{~g}_{\mathrm{mPF}} \mathrm{g}_{\mathrm{mPD}} \mathrm{r}_{\mathrm{ds}-\mathrm{P} 20}} .
$$

A third, designed to be non-dominant, pole is introduced by the driver loops at the gates of $\mathrm{M}_{\mathrm{ND}}$ and $\mathrm{M}_{\mathrm{PD}}$, high impedance nodes. Intuitively, by inspecting Equations (1) and (5) more carefully, it is evident that the impedance increases at a frequency roughly defined by $\mathrm{R}_{\mathrm{DS}-\mathrm{N} 20}$ and $\mathrm{C}_{\mathrm{GS}-\mathrm{ND}}$. The impedance can be estimated by

$$
\mathrm{Ro}_{\mathrm{LSD}} \approx \frac{\left\lfloor 1+\mathrm{s}\left(\mathrm{r}_{\mathrm{ds}-\mathrm{N} 20} \mathrm{C}_{\mathrm{GS}-\mathrm{ND}}\right)\right\rfloor}{\mathrm{g}_{\mathrm{mNF}} \mathrm{g}_{\mathrm{mND}} \mathrm{r}_{\mathrm{ds}-\mathrm{N} 20}} .
$$

In other words, at frequencies greater than the aforementioned pole, Ro LSD increases thereby establishing an additional pole in the main forward loop. Resistance $\mathrm{Ro}_{\mathrm{LSD}}$ behaves in a similar fashion. However, to insure stability of the local loops, the pole at this node is made dominant, being the only high impedance node in the loop. Simultaneously, though, to insure stability of the overall loop, this pole cannot be too low, otherwise overall phase margin of the main loop is compromised. Capacitors $\mathrm{C}_{\mathrm{C} 1}$ and $\mathrm{C}_{\mathrm{C} 4}$ were added for this reason. The reason behind resistors 
$\mathrm{R}_{\mathrm{C} 1}$ and $\mathrm{R}_{\mathrm{C} 2}$ and their connections to the gates of $\mathrm{M}_{\mathrm{NF}}$ and $\mathrm{M}_{\mathrm{PF}}$ have to do with the stability of the CMFB circuit.

The CMFB loop has two high impedance nodes, the one shared with the main loop, at the gates of $\mathrm{M}_{\mathrm{NF}}$ and $\mathrm{M}_{\mathrm{PF}}$, and one within the drivers themselves, at the gates of $\mathrm{M}_{\mathrm{ND}}$ and $\mathrm{M}_{\mathrm{PD}}$. For the CMFB circuit, the ac signals propagate through the drivers via source followers $\mathrm{M}_{\mathrm{NF}}$ and $\mathrm{M}_{\mathrm{PF}}$, which lead to the low impedance sources of $\mathrm{M}_{\mathrm{PB}}$ and $\mathrm{M}_{\mathrm{NB}}$ and, ultimately, to the high impedance gates of $\mathrm{M}_{\mathrm{ND}}$ and $\mathrm{M}_{\mathrm{PD}}$, before converting it to a current back in the CMFB circuit. Thus, for this loop to be stable, Miller compensation is used to split the two poles, which is why $\mathrm{C}_{\mathrm{C} 1}$ and $\mathrm{C}_{\mathrm{C} 4}$ are connected back to the gates of $\mathrm{M}_{\mathrm{PF}}$ and $\mathrm{M}_{\mathrm{NF}}$. Resistors $\mathrm{R}_{\mathrm{C} 1}$ and $\mathrm{R}_{\mathrm{C} 2}$ were added to bring the Right-Half Plane (RHP) zeros back into the Left-Half Plane (LHP) to help optimize phase margin. The gates of $\mathrm{M}_{\mathrm{NCMP}}$ and $\mathrm{M}_{\mathrm{NCMN}}$ constitute the third non-dominant poles of this loop. Since their respective resistances and associated capacitor values are low, they are easily kept at high frequencies. It is noted that when the alternative signal paths in the rail-to-rail control circuit $\left(\mathrm{M}_{\mathrm{N} 217}\right.$ and $\left.\mathrm{M}_{\mathrm{P} 214}\right)$ are used, no high impedance poles are added thereby preserving the stability conditions of the CMFB loop.

\section{F. Optimum Operation}

The amplifier's closed-loop output impedance can be estimated by dividing the result of Equation (1) by the gain of the main feedback loop,

$$
\mathrm{Ro}-\mathrm{CL} \approx \frac{\mathrm{RO}-\mathrm{LSD} / / \mathrm{Ro}-\mathrm{HSD}}{\mathrm{AV}_{V}} \leq \frac{1}{\mathrm{~g}_{\mathrm{mF}} \mathrm{r}_{\mathrm{o} 2} \mathrm{~g}_{\mathrm{mD}} \mathrm{AV}_{V}},
$$

where $\mathrm{R}_{\mathrm{O}-\mathrm{LSD}}$ and $\mathrm{R}_{\mathrm{O}-\mathrm{HSD}}$ are the output resistance of the LSD and HSD circuits, respectively. Clearly, for this approximation to be valid over the entire output voltage range, either the HSD or LSD must be functioning regardless of output voltage; otherwise, the output resistance of the drivers degrade since the localized feedback look is broken. This requires that the supply voltage 
be large enough to allow the HSD to assume control of the output before the LSD cuts off, and vice versa. Closer inspection of the output stage and rail-to-rail control circuitry reveals this condition is attainable only when the total supply voltage is greater than about $3.2 \mathrm{~V}$. For the HSD to function as described in Section II, $V_{\text {OUT }}$ must be at least $V_{T N}+V_{T P}$ greater than $V_{S S}$, as mandated by $M_{P F}$ and $M_{N 217}$. Similarly, in the LSD, $V_{\text {OUT }}$ must be at least $V_{T N}+V_{T P}$ below $V_{C C}$, as mandated by $\mathrm{M}_{\mathrm{P} 214}$ and $\mathrm{M}_{\mathrm{NF}}$. Otherwise the follower would be cut off and the alternate CMFB path would be activated. Thus, to insure that one driver circuit is always on, even in the middle of the range where the limitation is worst, the supply voltage should be roughly greater than $3.2 \mathrm{~V}$,

$$
\mathrm{V}_{\mathrm{CC}}-\mathrm{V}_{\mathrm{SS}} \geq 2 \mathrm{~V}_{\mathrm{TN}}+2 \mathrm{~V}_{\mathrm{TP}}+4 \mathrm{~V}_{\mathrm{DS}}
$$

Coincidentally, when the input voltage is lower than $3.2 \mathrm{~V}$, the circuit still has very low output impedance, since the output node is still part of the CMFB feedback loop through the alternate CMFB path.

\section{IV - Simulated RESUlts}

The amplifier was simulated and compared with other state-of-the-art class $A B$ amplifiers. A summary of this comparison is given in Table 1. The proposed circuit has the best peak output-current performance as well as the lowest quiescent-current flow, in other words, best efficiency, which is important in battery-operated environments. It is also capable of working down to supply voltages of $1.5 \mathrm{~V}$, the lowest of the competing amplifiers surveyed. Other parameters were similar. Open-loop gain was lower in the proposed circuit, however, since a single gain-stage topology was used.

Fig. 6 shows the current through driver transistors $M_{N D}$ and $M_{P D}$ as a function of common-mode output voltage, with a $1.5 \mathrm{~V}$ supply in Fig. 6(a) and a $6 \mathrm{~V}$ supply in Fig. 6(b). 
These plots demonstrate the true class $\mathrm{AB}$ behavior of the output stage over the full range of supply voltages. The input stage transconductance is shown in Fig. 7 as a function of the input common-mode voltage. The left side of the hump is the region where the PMOS differential pair is conducting and the right side is where the NMOS pair is conducting. As predicted, transconductance increases when both input pairs conduct and the peak $\mathrm{g}_{\mathrm{m}}$ is exhibited. Since the region for which both differential pairs conducted was narrow, the estimated peak transconductance was not attained; instead, a lower, less variable, response was shown.

The ac characteristics of the amplifier are shown in Fig. 8. Fig. 8(a) shows how the circuit gain varies with common-mode input voltage. Since $g_{m}$ is relatively constant, the gain variations mostly reflect changes in the output impedance of the gain stage, which are present due to modulation of the common-mode feedback signal. Fig. 8(b) shows supply rejection as a function of frequency for several different output voltages.

Fig. 9 shows the amplifier's response to a pulse on the input when configured for unity gain. Fig. 9(a) shows a rail-to-rail input pulse with a $1.5 \mathrm{~V}$ supply and the amplifier's rail-to-rail response when loaded with $10 \mathrm{k} \Omega$ and $100 \mathrm{pF}$. The output voltage is limited only by the required drain-source voltages of the driver transistors, $M_{N D}$ and $M_{P D}$. In Fig. 9(b), the pulse goes from -1 to $1 \mathrm{~V}$ and the output is connected to a $350 \Omega / 100 \mathrm{pF}$ load to ground to show the circuit's behavior as it is forced to quickly go from sinking to sourcing current. The propagation delay of the circuit was roughly between 2 and $2.5 \mu$ s, showing very stable characteristics.

The circuit's output impedance is shown in Fig. 10 as a function of common-mode output voltage and load current. The DC output resistance is on the order of hundreds of micro-ohms in Figs. 10(a) and (b), for the case of higher supply voltages. These figures are designed to show how the output impedance remains low throughout the operating range of voltages and loads, 
even when there is little current being sourced or sunk. In Fig 10(c), the output impedance is increased by approximately an order of magnitude when the supply voltage is dropped to $1.5 \mathrm{~V}$.

$$
\text { V - CONCLUSIONS }
$$

A CMOS low voltage, rail-to-rail, class $\mathrm{AB}$ amplifier with high output drive and low output impedance was presented. Novel high side and low side output drivers, utilizing source followers in conjunction with common source drivers, were shown to significantly lower the output impedance of the amplifier, while still allowing rail-to-rail operation. The amplifier is fully functional with supplies as low as $1.5 \mathrm{~V}$ and optimum operation, with regards to output impedance, is achieved at supply voltages greater than $3.2 \mathrm{~V}$. A typical quiescent current of less than $140 \mu \mathrm{A}$ was achieved over the full output current range, with a maximum output current of $\pm 7 \mathrm{~mA}$ with a $\pm 3 \mathrm{~V}$ supply. Low voltage rail-to-rail input/output operation with low quiescent current flow and high output current make it ideal for battery-powered applications where efficiency is paramount for battery life and extended dynamic range is intrinsic for performance. 


\section{REFERENCES}

[1] Soundarapandian Karthikeyan, Siamak Mortezapour, Anilkumar Tamineedi, and Edward K. F. Lee, "Low Voltage Analog Circuit Design Based on Biased Inverting Opamp Configuration", IEEE Trans. Circuits and Systems II, vol. 47, pp. 176-184, March 2000.

[2] Satoshi Sakurai and Mohammed Ismail, "Robust Design of Rail-to-Rail CMOS Operational Amplifiers for a Low Power Supply Voltage”, IEEE J. Solid-State Circuits, vol. 31, pp. 146-156, Feb. 1996.

[3] Klaas-Jan de Langen, Johan H. Huijsing, "Compact Low-Voltage Power-Efficient Operational Amplifier Cells for VLSI”, IEEE J. Solid-State Circuits, vol. 33, pp. 1482-1496, Oct. 1998

[4] Randall L. Geiger, Phillip E. Allen, Noel R. Strader, VLSI Design Techniques for Analog and Digital Circuits, pp. 466-473, McGraw-Hill, 1990.

[5] Joseph N. Babanezhad, "A Low-Output-Impedance Fully Differential Op Amp with Large Output Swing and Continuous-Time Common-Mode Feedback", IEEE J. Solid-State Circuits, vol. 26, pp. 1825-1833, Dec. 1991.

[6] Jeroen Fonderie, Marinus M. Maris, Erik J. Schnitger, and Johan H. Huijsing, "1-V Operational Amplifiers with Rail-to-Rail Input and Output Ranges”, IEEE J. Solid-State Circuits, vol. 24, pp. 1551-1559, Dec. 1989.

[7] J. Francisco Duque-Carrillo, Jose L. Ausin, Guido Torelli, Jose M. Valverde, and Miguel A. Dominguez, "1-V Rail-to-Rail Operational Amplifiers in Standard CMOS Technology", IEEE J. Solid-State Circuits, vol. 35, pp. 33-44, Jan. 2000.

[8] Paul R. Gray and Robert G. Meyer, Analysis and Design of Analog Integrated Circuits, John Wiley \& Sons, 1993. 
Table 1. Summary of class AB amplifier performance.

\begin{tabular}{|c|c|c|c|c|c|}
\hline \multicolumn{2}{|l|}{ Parameter } & $\begin{array}{l}\text { Proposed } \\
\text { Amplifier }\end{array}$ & [5] & {$[3]$} & Units \\
\hline \multicolumn{2}{|l|}{ Minimum supply voltage } & 1.5 & $\overline{5}$ & 1.8 & $\overline{\mathrm{V}}$ \\
\hline \multicolumn{2}{|l|}{ Supply current } & 140 & 714 & 230 & $\mu \mathrm{A}$ \\
\hline \multicolumn{2}{|l|}{ Peak output current } & \pm 7.0 & \pm 4.0 & 1.2 & $\overline{\mathrm{mA}}$ \\
\hline \multicolumn{2}{|l|}{ Input offset voltage } & 5 & -0.5 & 6 & $\mathrm{mV}$ \\
\hline \multirow[t]{2}{*}{$\mathrm{CM}$ input range } & $\max$ & $\mathrm{V}_{\mathrm{DD}}$ & $\mathrm{V}_{\mathrm{DD}}-1.2$ & $\mathrm{~V}_{\mathrm{DD}}$ & $\mathrm{V}$ \\
\hline & $\min$ & $\mathrm{V}_{\mathrm{SS}}$ & $\mathrm{V}_{\mathrm{SS}}$ & $\mathrm{V}_{\mathrm{SS}}$ & V \\
\hline \multirow{2}{*}{$\begin{array}{l}\text { Output voltage range } \\
\qquad(\text { Iout }=0 \mathrm{~mA})\end{array}$} & $\max$ & $\mathrm{V}_{\mathrm{DD}}$ & $\mathrm{V}_{\mathrm{DD}}$ & $V_{D D}$ & $\mathrm{~V}$ \\
\hline & $\min$ & $\mathrm{V}_{\mathrm{SS}}$ & $\mathrm{V}_{\mathrm{SS}}$ & $\mathrm{V}_{\mathrm{SS}}$ & $\mathrm{V}$ \\
\hline \multirow{2}{*}{$\begin{array}{l}\text { Output voltage range } \\
\text { (Iout }= \pm 4.0 \mathrm{~mA} \text { ) }\end{array}$} & $\max$ & $\mathrm{V}_{\mathrm{DD}}-0.3$ & $\mathrm{~V}_{\mathrm{DD}}-0.3$ & $N / A$ & $\mathrm{~V}$ \\
\hline & $\min$ & $\mathrm{V}_{\mathrm{SS}}+0.3$ & $\mathrm{~V}_{\mathrm{SS}}+0.3$ & $N / A$ & $\mathrm{~V}$ \\
\hline \multicolumn{2}{|c|}{$\operatorname{THD}\left(1 \mathrm{kHz}, 1 \mathrm{~V}, \mathrm{R}_{\mathrm{L}}=10 \mathrm{k} \Omega\right)$} & -48 & $N / A$ & -41 & $\mathrm{~dB}$ \\
\hline \multicolumn{2}{|l|}{ Unity-gain frequency } & 300 & 500 & 4000 & $\mathrm{kHz}$ \\
\hline \multicolumn{2}{|l|}{ Phase margin } & 80 & 70 & 67 & $\circ$ \\
\hline \multicolumn{2}{|l|}{ Open-loop gain } & 65 & 95 & 86 & $\mathrm{~dB}$ \\
\hline \multicolumn{2}{|l|}{ Slew rate } & 0.4 & 0.4 & 4.5 & $\mathrm{~V} / \mu \mathrm{s}$ \\
\hline \multicolumn{2}{|l|}{ Power supply rejection } & 75 & 100 & $N / A$ & $\mathrm{~dB}$ \\
\hline \multicolumn{2}{|l|}{ Max capacitive load } & 100 & 100 & $N / A$ & $\mathrm{pF}$ \\
\hline
\end{tabular}




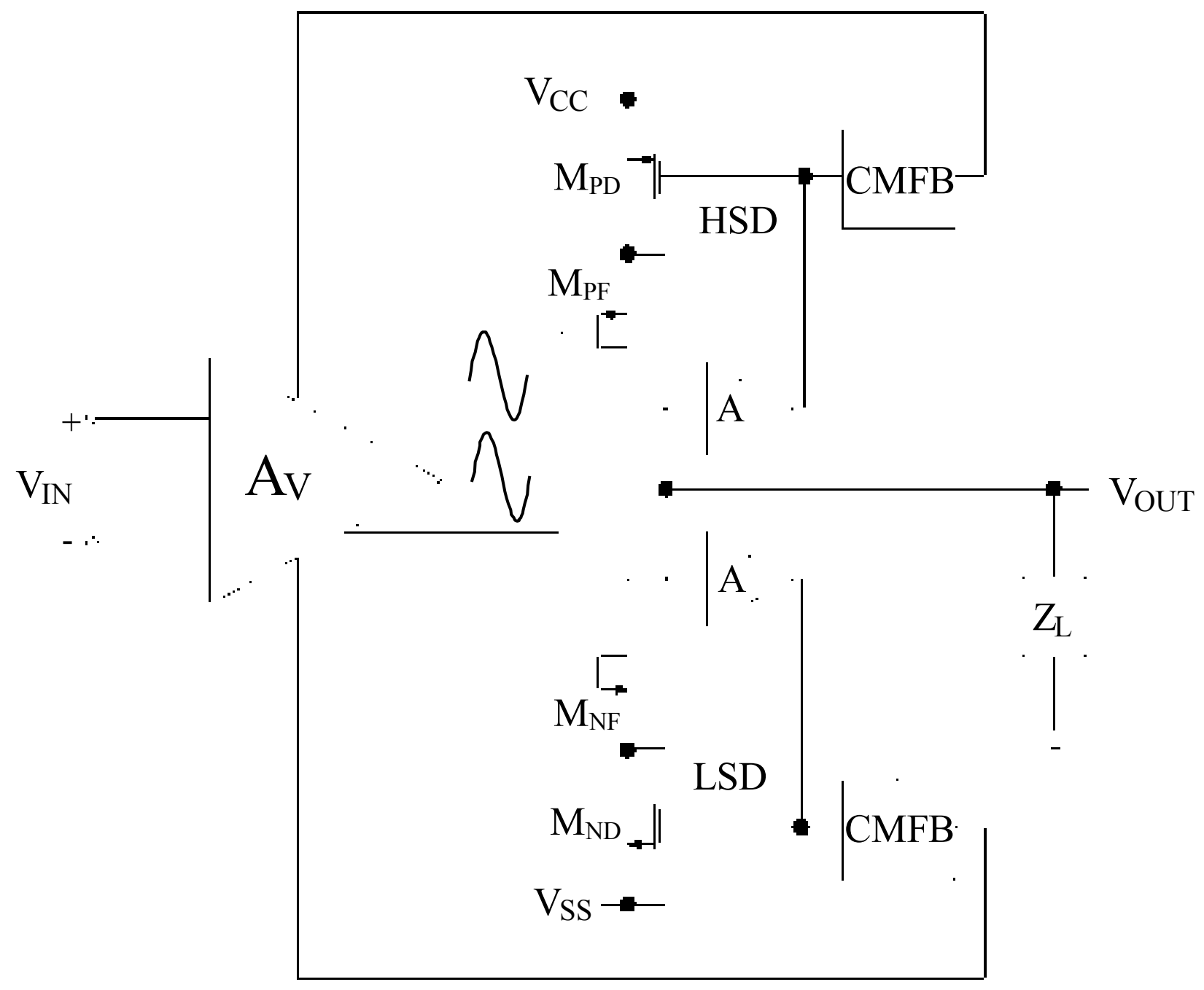

Fig. 1. Circuit topology of the proposed class AB amplifier. 


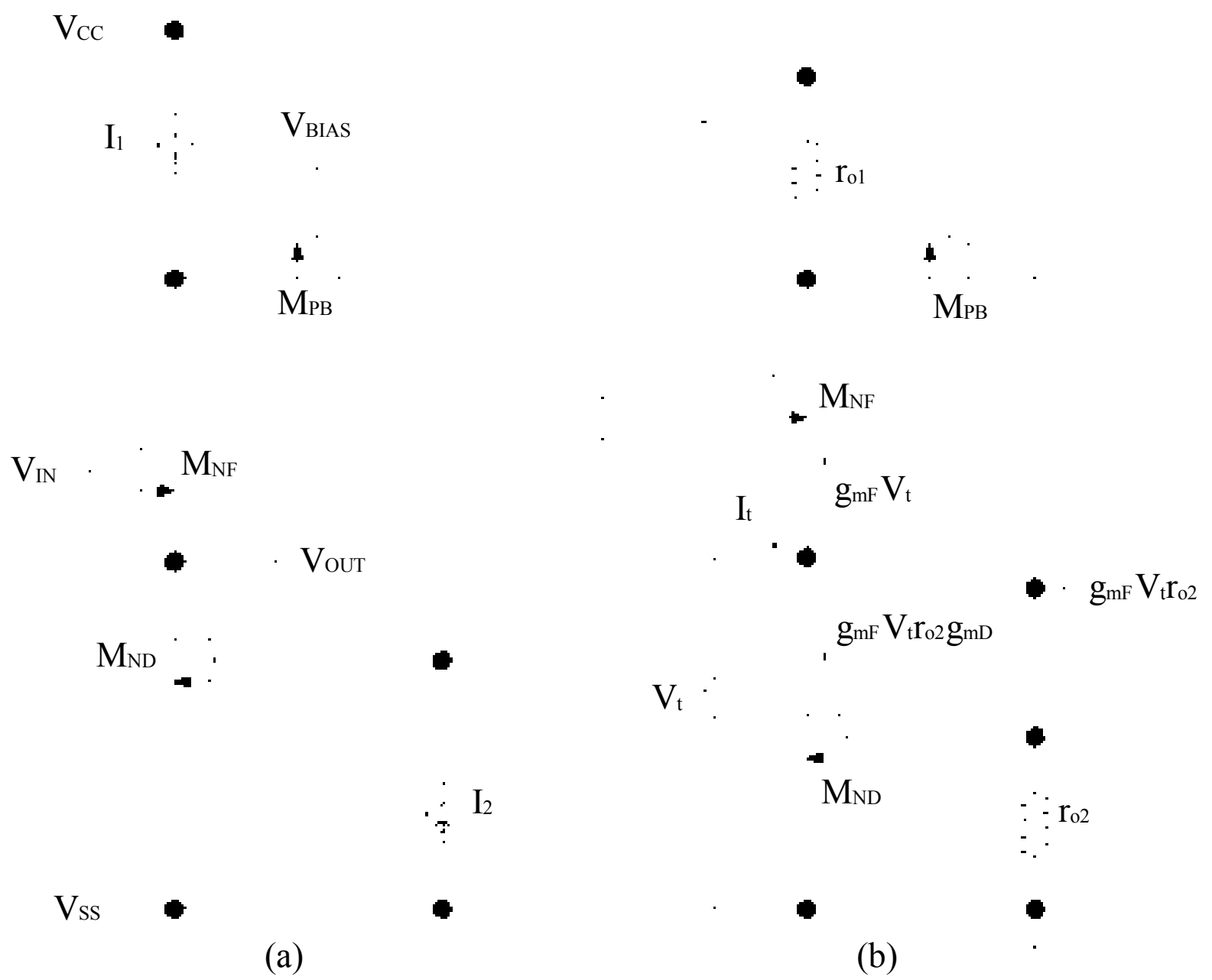

Fig. 2. (a) Simplified circuit diagram of the low side output driver (LSD) and (b) the ac equivalent circuit used to calculate its output impedance. 